\title{
DEVELOPMENT OF RADIATION DETECTOR (RADIATION MODULE) WITH THREE DIFFERENT SENSORS FOR SPACE APPLICATIONS
}

\author{
Bugra Kocaman ${ }^{1,2^{*}}$, Mehmet Kopru', Bekir Solak ${ }^{1}$, Murat Harmandali ${ }^{1}$, Eylem Guven ${ }^{2}$, Ercan Yilmaz ${ }^{3,4}$ \\ 'TUBITAK Space Technologies Research Institute (TUBITAK UZAY), METU Campus, Ankara, Turkey \\ ${ }^{2}$ Division of Nanotechnology and Nanomedicine, Hacettepe University, Beytepe Campus, Ankara, Turkey \\ 3Nuclear Radiation Detectors Applications and Research Center, Bolu Abant Izzet Baysal University, Bolu, Turkey \\ 4Physics Department, Faculty of Arts and Sciences Bolu Abant Izzet Baysal University, Bolu, Turkey
}

\begin{abstract}
The novel domestic radiation sensors - called "NürFETs" - can be used to measure Total Ionizing Dose (TID) on the mission orbit. NürFET responses are compared with two different sensors on the market with demonstrated performance. The radiation detector reader has been designed by the Space Technologies Research Institute (TUBITAK UZAY) and named MURaD and it contains three distinctive sensors, namely the aforementioned Nuclear Radiation Sensing Field Effect Transistor (NürFET), the p-channel RADFET, and the Floating Gate Dosimeter (FGDOS), respectively. They are used to measure TID comparatively and separately. The whole radiation module contains three different sensors which are exposed to gamma radiation on the ground via a Co-6o source and the functional and/or parametric test results are presented.
\end{abstract}

Keywords: NürFET, RADFET, FGDOS, TID, dosimeter, radiation detector, space radiation

\section{INTRODUCTION}

There are many types of sensors and detectors in literature and application which are used to measure the radiation exposure level for different purposes. However, it is difficult to identify and determine the ideal way to measure TID because it depends on growth technology, semiconductor type, mission requirements, radiation environment, etc. The transistors with MOS technology can be used as radiation sensors and this topic has been addressed and explained comprehensively in many studies [1], [2], [3], [4].

In this paper, it was focused and worked on measuring radiation by the help of three different radiation-sensitive sensors in our novel detector called MURaD. The first sensor, Nuclear Radiation Sensing Field Effect Transistors (NürFETs), is a p-channel radiation-sensitive MOSFET and it is manufactured by the Nuclear Radiation Detectors Application and Research Center (NÜRDAM) in Bolu, Turkey. It is a native radiation sensor and it provides many advantages thanks to its novel dielectric materials and thicknesses [5]. The second sensor is Varadis RADFET VTo1 (formerly TY1003) pMOS dosimeter manufactured by Varadis (formerly Tyndall Works). The third sensor is a Floating Gate Dosimeter (FGDOS) manufactured by Sealicon (formerly IC-Malaga). The performances of RADFET and FGDOS sensors have been utilized in many different radiation environments

\footnotetext{
*bugra.kocaman@tubitak.gov.tr
}

[6], [7], [8], [9]. So, using three different sensors referenced above, it is possible to reliably check and compare the TID measurement results.

\section{RADIATION DETECTOR}

Figure 1 shows the functional block diagram describing the working principle of the detector. MURaD is powered by a $5 \mathrm{~V}$ power supply and there are $\mathrm{HF} / \mathrm{LF}$ rejection circuitries to filter/reduce noise in the detector. In order to measure the changes in the sensors, constant current sources are used in the sensor electronics. Shifts in the threshold voltages are converted into a digital signal by the help of a 24-bit analog to digital converter (ADC), and a signal processing unit analyses those signals to measure the total dose. The detector transmits and receives signals by the help of the UART serial communication protocol.

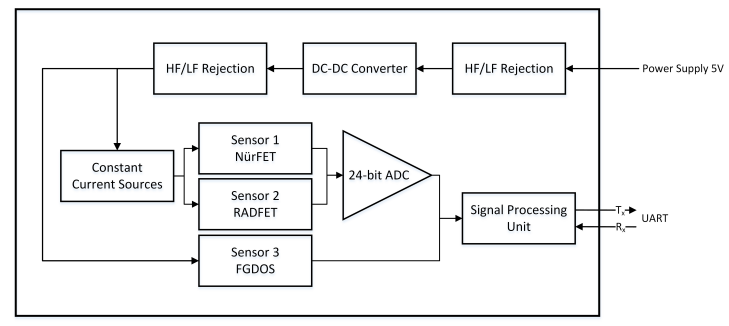

Figure 1. Functional block diagram of MURaD 
MOSFETs are a variety of field-effect transistors (FET). MOSFETs are manufactured with MOS technology, and they are used extensively in different types of analog and digital applications. RADFETs are radiation-sensitive, purpose-oriented MOSFETs, and they are manufactured to indicate shifts in threshold voltage because of radiation. RADFETs are also pchannel MOSFETs and their working principle is based on the shift in threshold voltage as well. When a MOSFET sensor is exposed to radiation, it creates trapped charges in the gate oxide and interface layer, and radiation causes changes in the internal resistance of this layer and consequently in threshold voltage. Since the shift in threshold voltage is proportional to the radiation exposure level, it is possible to identify the radiation exposure level with measuring the shift in threshold voltage [10], [11], [12].

NÜRDAM's NürFETs (Sensor 1) and Varadis' RADFET VTo1 (Sensor 2) share a similar working principle to measure the ionizing dose. Figure 2 depicts the general structure of the p-channel MOSFETs under ionizing radiation.

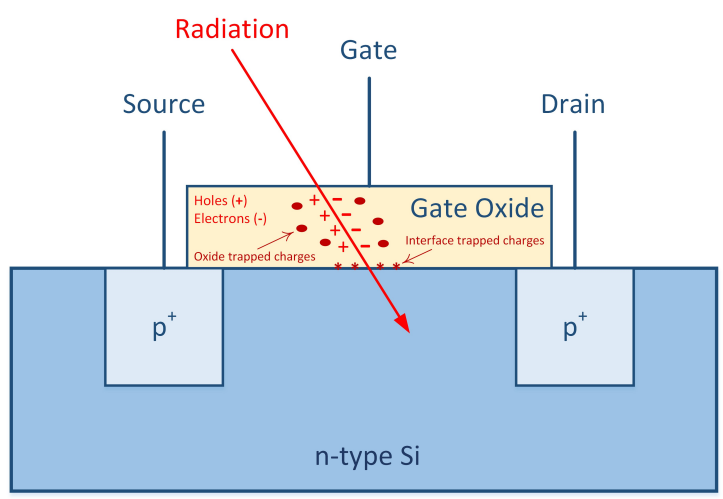

Figure 2. Radiation induced charges because of ionizing radiation in MOSFET structure

As a radiation sensor, p-channel MOSFETs provide many advantages, such as smaller package size, low power consumption and ability to measure even a higher radiation dose up to $10^{6} \mathrm{rad}(\mathrm{Mrad})$ [13].

The third sensor in MURaD is Sealicon's Floating Gate Dosimeter (FGDOS) (Sensor 3). Working principle of Sealicon's FGDOS is based on the transition in capacitance characteristics in the sensor. The field oxide layer can be assumed as the dielectric part of a capacitor, and when the field oxide layer (or dielectric) is exposed to ionizing radiation, the capacitors in sensors are discharged. Discharge mechanism is proportional to ionizing radiation; therefore, it can be used as a detector to measure TID. FGDOS has two radiation-sensitive sensors inside. One of them is a radiation-sensitive sensor and its frequency changes with radiation exposure. The other one is the reference sensor which identifies the charge/recharge cycle. FGDOS provides many advantages. For example, it has a higher resolution than p-channel MOSFETs (RADFET) and, since it gives digital output, the general circuit design can be simplified. It has been used in several space missions, for instance, 4M Lunar Flyby Mission from LuxSpace, an OHB company, and Chinese Chang'e 5-T1 test spacecraft [6], [8], [14], [15], [16].
Native detector MURaD is the first platform to host NürFETs as a space radiation sensor. Therefore, the performance of NürFETs will be compared and analyzed with respect to RADFET and FGDOS for TID measurement. Figure 3 shows the comparison of the prototype $\mathrm{PCB}$ and NürFET next to a $1 €$ coin.

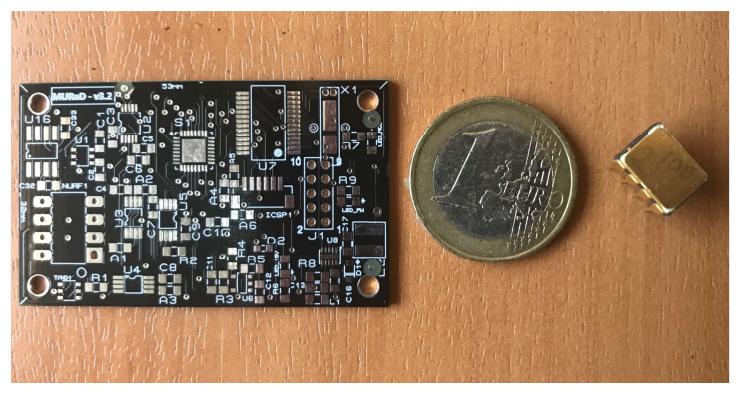

Figure 3. MURaD PCB and NürFET compared with 1 Euro coin

\section{RADIATION TEST, MEASUREMENTS AND RESUltS}

In order to demonstrate and verify the proper functional and parametric results of our detector, it was subjected to the Co-6o gamma radiation test in the Turkish Atomic Energy Authority (TAEK), Sarayköy Nuclear Research and Training Center (SANAEM) facilities [17]. The photographs of the facility and Co60 source can be seen in Figure 4. Radiation dose rate was approximately $7 \mathrm{krad} / \mathrm{h}$ and it was measured by alanine dosimeters. The uncertainty in alanine dosimeters is less than $4 \%$.

The communication protocol has been determined as RS-422. The measurements were read and stored via LabView-based computer software in real-time. The voltage levels over NürFET and RADFET were converted into the radiation dose and afterwards compared with the radiation dose over FGDOS.

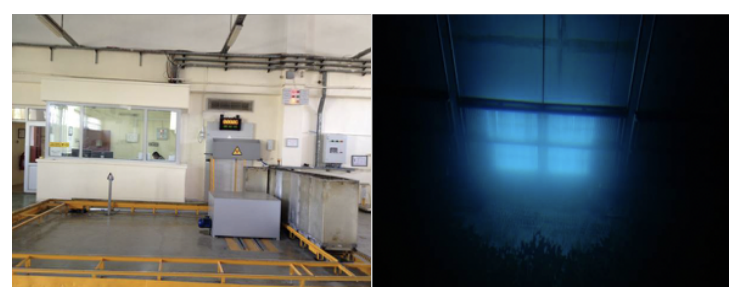

Figure 4. TAEK SANAEM Gamma Radiation Facility and Co-6o source

At the beginning (pre-irradiation), the threshold voltages of NürFETs were measured approximately as $7.39 \mathrm{~V}$ for $10 \mu \mathrm{A}$, and $10.042 \mathrm{~V}$ for $100 \mu \mathrm{A}$. The threshold voltage of RADFET was measured approximately as $2.028 \mathrm{~V}$ for $10 \mu \mathrm{A}$. FGDOS has two internal sensors and also these sensors have their own reference frequency. Frequency of Sensor-o was measured approximately as $130 \mathrm{kHz}$ and a reference frequency of Sensor-o was measured approximately as $127 \mathrm{kHz}$. Moreover, the frequency of Sensor-1 was measured approximately as $128 \mathrm{kHz}$ and a reference frequency of Sensor-1 was measured approximately as $127 \mathrm{kHz}$. 
Irradiation was performed in two steps. In the first step, three (3) sensors (NürFETs, RADFET, and FGDOS) were successfully irradiated. However, the charge/recharge cycle of FGDOS could not be maintained because of the high level of radiation dose rate exposure during the test. In our experimental measurements, it was discovered that the recharge rate of FGDOS was about $2.5 \mathrm{kHz} / \mathrm{min}$. Throughout the radiation test, FGDOS was consistently exposed to a higher radiation dose than its practical design limits; therefore, it could not be recharged again. At the beginning of the radiation test, the first charge/recharge phase was observed and obtained and the figures can be seen in Section 3.3. In the second step, FGDOS was removed from the rest of the circuitry because it congested the detector electrically. Step 35 is the beginning and Step 41 is the end of the first irradiation step. The time interval between each step is approximately 30 seconds in the first irradiation step. In the second irradiation step, the time interval between each step is approximately 17 seconds.

\subsection{NürFET Measurement Results}

There are two current sources, which are $100 \mu \mathrm{A}$ and $10 \mu \mathrm{A}$, used for NürFETs to see the possible responses of the circuitry. Eventually, the results for NürFETs can be seen in Figure 5, Figure 6, Figure 7, and Figure 8, respectively. In Figure 5 and Figure 7, it can be seen that there is an instability in measurements before the radiation test. Contaminations in production phases/environment, potential flaws in manufacturing process and/or some structural defects in the oxide layer can be responsible for this instability.

For the $100 \mu \mathrm{A}$ current source, the threshold voltage of NürFETs shifted from $10.042 \mathrm{~V}$ to $10.063 \mathrm{~V}$. The first irradiation step lasted approximately 3 minutes. The irradiation was started at step number 35. Figure 5 shows the measurements before and during the irradiation.

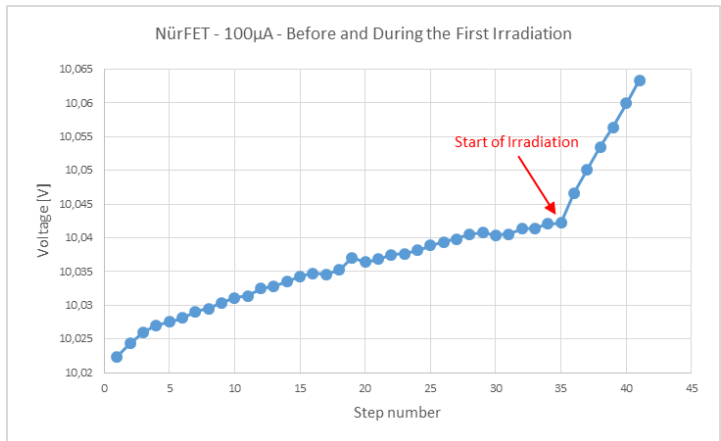

Figure 5. NürFETs with $100 \mu \mathrm{A}$ current source (before and during the first irradiation)

In order to show the voltage shift in detail because of limited time of radiation exposure, Figure 6 was plotted separately. In the first irradiation, (biased with $100 \mu \mathrm{A}$ ) NürFET's exposed radiation level (declared by TAEK) was approximately 350 rad. This exposed radiation level shifted the threshold voltage $0.021 \mathrm{~V}$.

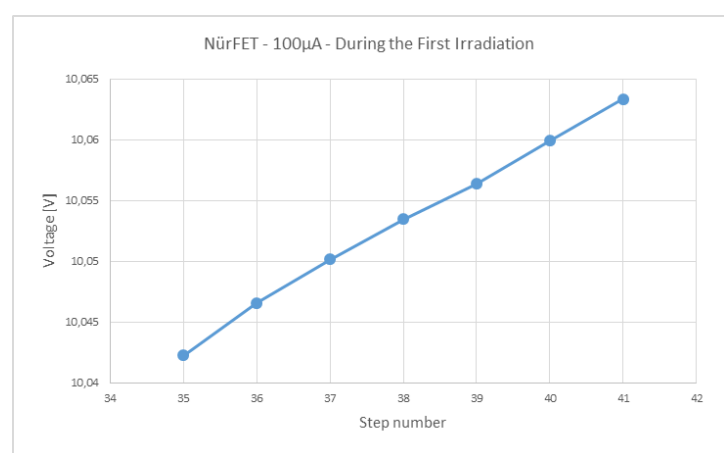

Figure 6. NürFETs with $100 \mu \mathrm{A}$ current source (during the first irradiation)

For the $10 \mu \mathrm{A}$ current source, the threshold voltage of NürFETs shifted from $7.390 \mathrm{~V}$ to $7.410 \mathrm{~V}$. The first irradiation step lasted approximately 3 minutes. The irradiation was started at step number 35. Figure 7 , shows the measurements before and during the irradiation.

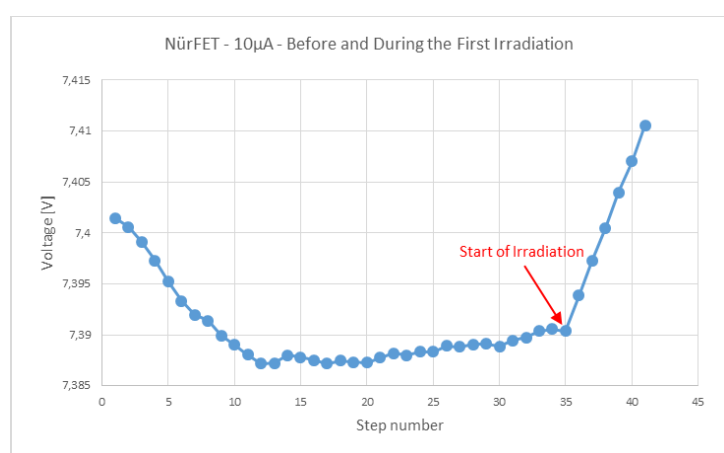

Figure 7. NürFETs with $10 \mu \mathrm{A}$ current source (before and during the first irradiation)

In order to show the voltage shift in detail because of radiation exposure in limited time, Figure 8 was plotted separately. In the first irradiation, (biased with $10 \mu \mathrm{A}$ ) NürFET's exposed radiation level (declared by TAEK) was approximately $350 \mathrm{rad}$. This exposed radiation level shifted the threshold voltage $0.020 \mathrm{~V}$.

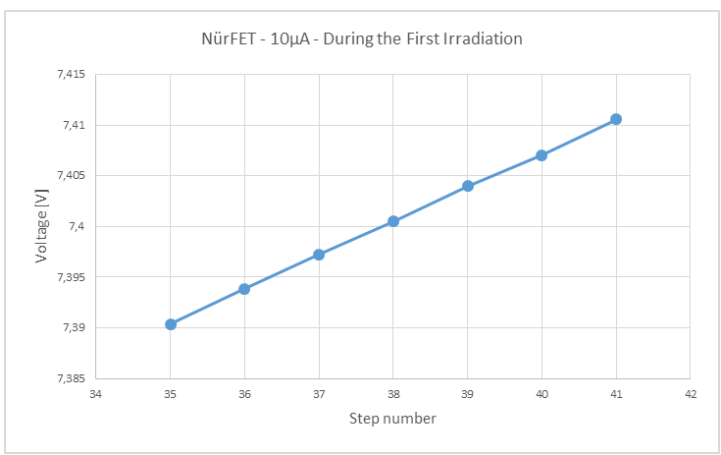

Figure 8. NürFETs with $10 \mu \mathrm{A}$ current source (during the first irradiation)

In Figure 9 and Figure 10, the results of the second irradiation step can be seen. The second irradiation step lasted approximately 45 minutes and NürFET's 
exposed radiation level (declared by TAEK) was approximately $5.25 \mathrm{krad}$.

For the NürFET biased with $100 \mu \mathrm{A}$ current source, the threshold voltage shifted from $10.110 \mathrm{~V}$ to $10.470 \mathrm{~V}$.

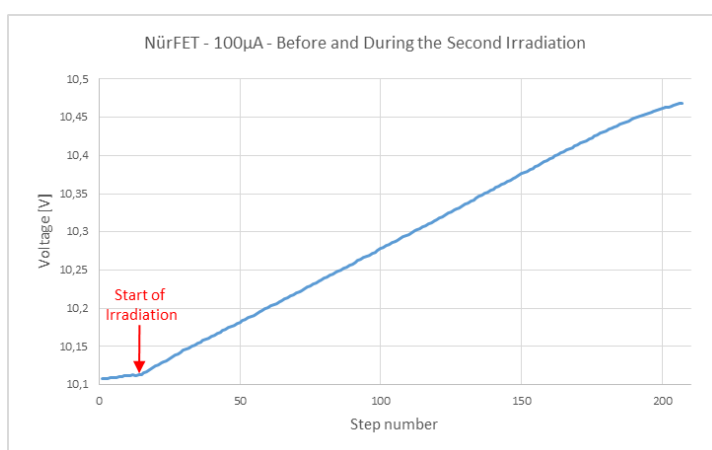

Figure 9. NürFETs with $100 \mu \mathrm{A}$ current source (before and during the second irradiation)

For the $10 \mu \mathrm{A}$ current source, the threshold voltage of NürFETs shifted from $7.474 \mathrm{~V}$ to $7.946 \mathrm{~V}$.

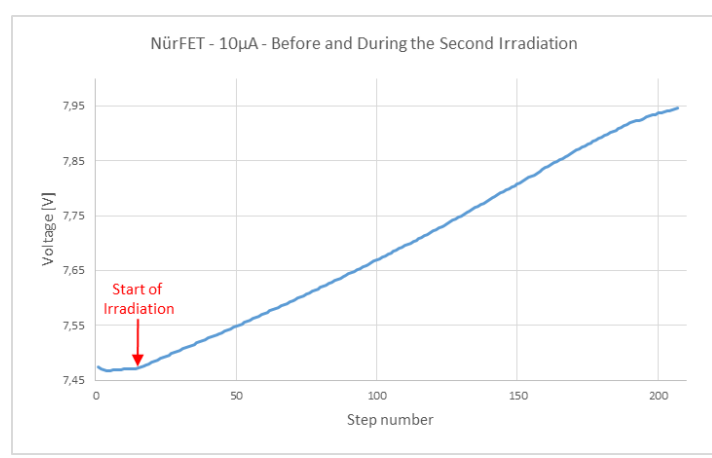

Figure 10. NürFETs with 10 $\mu$ A current source (before and during the second irradiation)

In the second irradiation step, exposed radiation level (declared by TAEK) was approximately $5.25 \mathrm{krad}$. The voltage shifts of NürFET were determined as 0.360 $\mathrm{V}$ and $0.472 \mathrm{~V}$ for $100 \mu \mathrm{A}$ and $10 \mu \mathrm{A}$ current sources, respectively.

\subsection{RADFET Measurement Results}

In Figure 11 and Figure 12, the result of the first irradiation step can be seen for Tyndall's RADFET. For the $10 \mu \mathrm{A}$ current source, the threshold voltage of RADFET was shifted from $2.028 \mathrm{~V}$ to $2.173 \mathrm{~V}$. The first irradiation step lasted approximately 3 minutes. The irradiation was started at step number 35 . Figure 11 shows the measurements before and during the irradiation.

In order to show the voltage shift in detail because of limited time of radiation exposure, Figure 12 was plotted separately. In the first irradiation, Tyndall RADFET's exposed radiation level (declared by TAEK) was approximately 350 rad. This exposed radiation level shifted the threshold voltage $0.145 \mathrm{~V}$. Exposed radiation level calculated/measured according to the datasheets provided by RADFET's manufacturer (Varadis) as $300 \mathrm{rad}$.

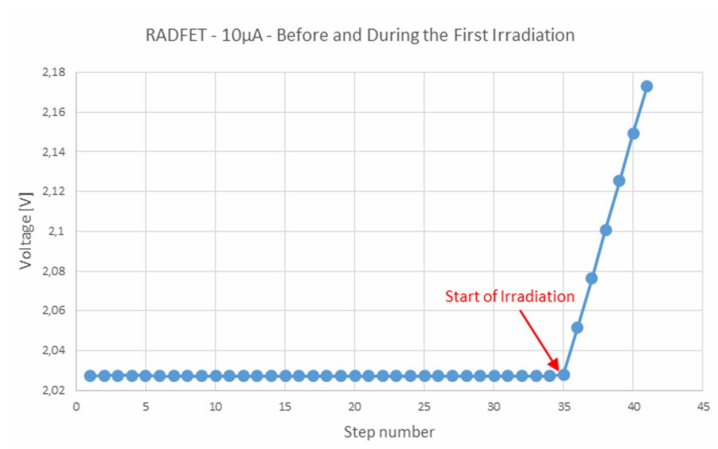

Figure 11. Tyndall RADFET with $10 \mu \mathrm{A}$ current source (before and during the first irradiation)

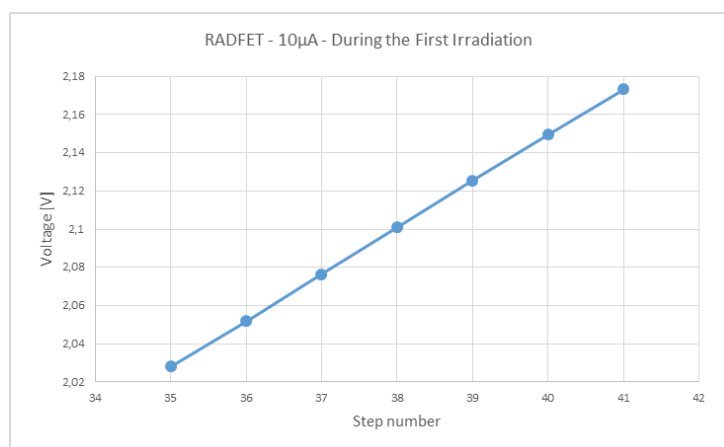

Figure 12. Tyndall RADFET with $10 \mu \mathrm{A}$ current source (during the first irradiation)

In Figure 13, the result of the second irradiation step can be seen for Tyndall's RADFET. For the $10 \mu \mathrm{A}$ current source, the threshold voltage of RADFET was shifted from $2.548 \mathrm{~V}$ to $3.874 \mathrm{~V}$. The second irradiation step lasted approximately 45 minutes. In the second irradiation, exposed radiation level (declared by TAEK) was approximately $5.25 \mathrm{krad}$. This exposed radiation level shifted the threshold voltage 1.326 V. Exposed radiation level calculated/measured according to the datasheets provided by RADFET's manufacturer (Varadis) as $5.190 \mathrm{krad}$.

Threshold voltage changes could not be traced reliably after a certain point because of our detector's (MURaD) circuitry constraints. To clarify, the analogto-digital converter (ADC) in $\mathrm{MURaD}$, which is responsible for voltage reference, is able to follow only up to approximately $4 \mathrm{~V}$; therefore, it could not be possible to obtain reasonable result after $3.874 \mathrm{~V}$.

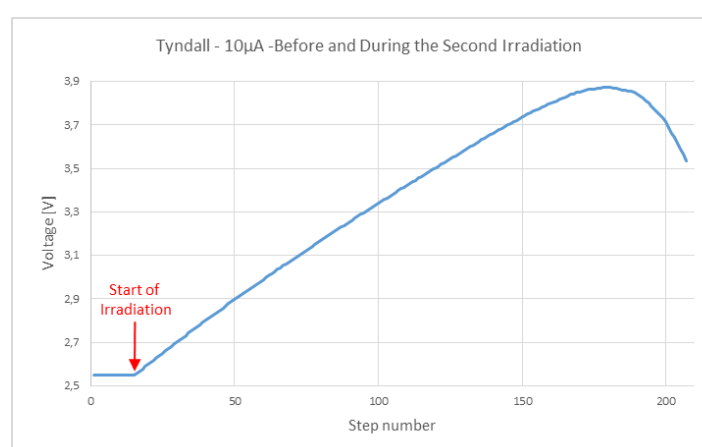

Figure 13. Tyndall RADFET with $10 \mu \mathrm{A}$ current source (before and during the second irradiation) 
RADFET (with $400 \mathrm{~nm}$ oxide thickness) and NürFET (with $300 \mathrm{~nm}$ oxide thickness) are p-type MOSFETs and their working principle is similar under the radiation. However, as it can be also seen from the irradiation results, their radiation sensitivity is different because they have different oxide layer thicknesses and their oxide layer processing techniques are not the same. Obviously, RADFET have better radiation sensitivity than NürFET.

\subsection{FGDOS Measurement Results}

The first irradiation step lasted approximately 3 minutes. FGDOS could not be recharged because of the high level of radiation dose rate and exposure. In consequence of this recharge problem, FGDOS was removed from rest of the circuitry with the means of software. Sensor-o's and its reference frequencies were measured around $130 \mathrm{kHz}$ and $127 \mathrm{kHz}$, respectively. After the first irradiation, Sensor-o's frequency decreased from $130 \mathrm{kHz}$ to $111 \mathrm{kHz}$. In Figure 14 and Figure 15 the result of the first irradiation step can be seen for FGDOS' Sensor-o. The irradiation was started at step number 35 . Figure 14 shows the measurements before and during the irradiation.

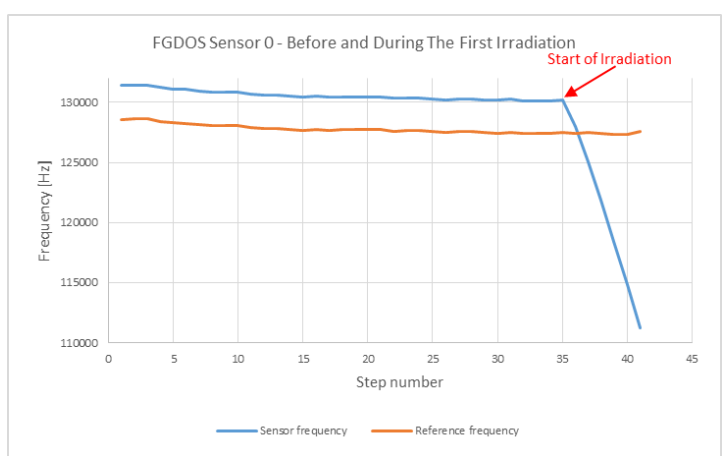

Figure 14. FGDOS Sensor-o response (before and during the first irradiation)

In order to show the voltage shift in detail because of limited time of radiation exposure, Figure 15 was plotted separately. In the first irradiation, exposed radiation level (declared by TAEK) was approximately 350 rad. This exposed radiation level shifted the threshold voltage 0.145 V. Exposed radiation level calculated/measured according to the datasheets provided by FGDOS' manufacturer (Sealicon) as 380 rad.

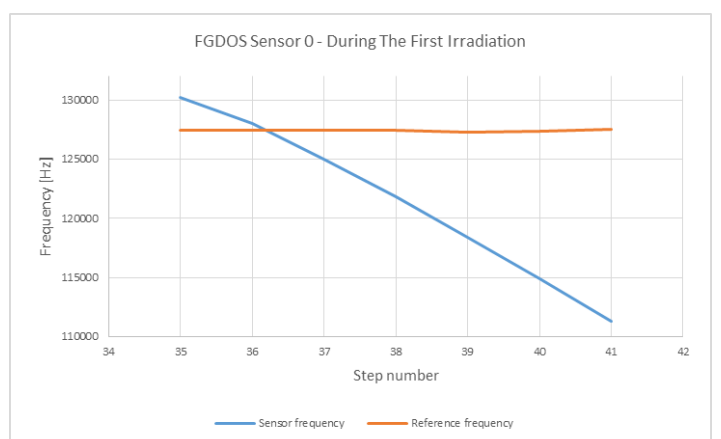

Figure 15. FGDOS Sensor-o response (during the first irradiation)
Sensor-1's and reference frequencies were measured around $128 \mathrm{kHz}$ and $127 \mathrm{kHz}$, respectively. After the first irradiation, Sensor-1's frequency decreased from $128 \mathrm{kHz}$ to $109 \mathrm{kHz}$. In Figure 16 and Figure 17, the result of the first irradiation step can be seen for FGDOS' Sensor-1. The irradiation was started at step number 35. Figure 16 shows the measurements before and during the irradiation.

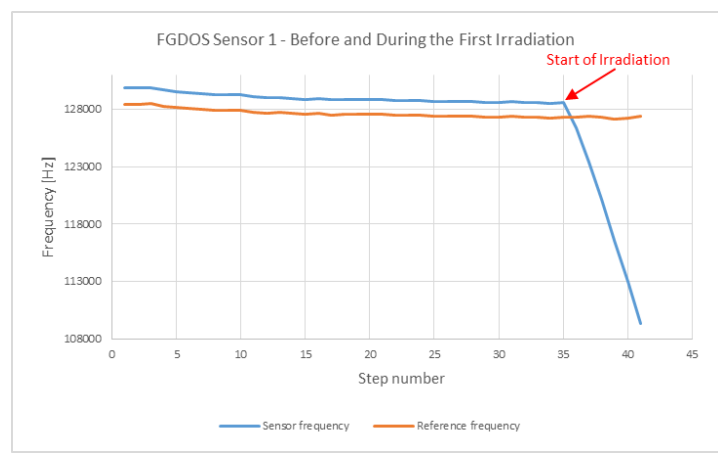

Figure 16. FGDOS Sensor-1 response (before and during the first irradiation)

In order to show the voltage shift in detail because of limited time of radiation exposure, Figure 17 was plotted separately. In the first irradiation, exposed radiation level (declared by TAEK) was approximately $350 \mathrm{rad}$. This exposed radiation level shifted the threshold voltage $0.145 \mathrm{~V}$. Exposed radiation level calculated/measured according to the datasheets provided by FGDOS' manufacturer (Sealicon) as 380 rad.

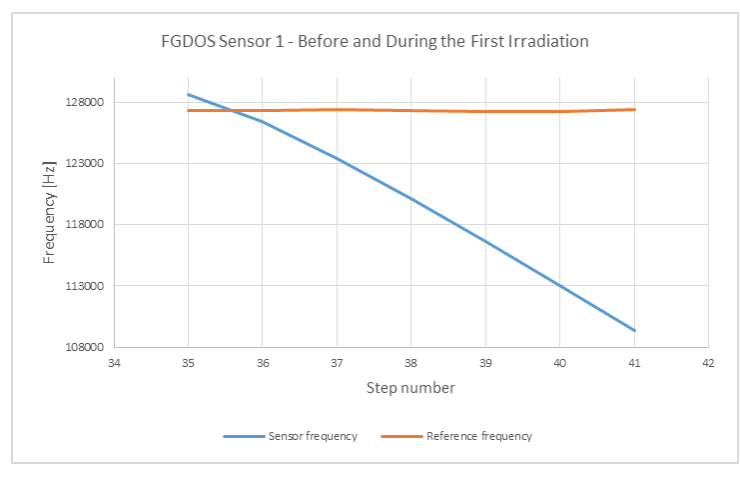

Figure 17. FGDOS Sensor-1 response (during the first irradiation)

\section{CONCLUSION}

The performances of 3 different radiation sensors and the detector reader (MURaD) have been tested under radiation exposure as well as examined, reported and explained. As it has been pointed out in this paper, one of the most important features and requirements for radiation measurement is the linearity of the detector. In our paper, we have proved this fact and shared the results showing that MURaD can achieve a linearity of this nature at least up to a certain level.

It is planned that the final version of MURaD is going to be integrated in a satellite to measure the TID radiation in the mission orbit. Some minor updates in 
MURaD's design are being planned at the componentlevel. Additionally, rad-tolerant and/or rad-hard components can be used in MURaD to measure radiation more precisely and reliably for harsher radiation environments.

This study and detector R\&D activity are very important for both national and international aspects. For the Turkish Space Industry, MURaD is going to be the first radiation detector/monitor to be commissioned in space. Additionally, and internationally, MURaD is going to provide invaluable space weather and radiation data of related mission orbit. The eventual information is going to help us discover the radiation effect phenomena in greater detail and design our satellite to be more reliable in our best interest.

\section{REFERENCES}

1. N. Bhat, J. Vasi, "Interface-state generation under radiation and high-field stressing in reoxidized nitrided oxide MOS capacitors," IEEE Trans. Nucl. Sci., vol. 39, no. 6, pp. 2230 - 2235, Dec. 1992. DOI: $10.1109 / 23.211425$

2. L. Adams, A. Holmes-Siedle, "The Development of an MOS Dosimetry Unit for Use in Space," IEEE Trans. Nucl. Sci., vol. 25, no. 6, pp. 1607 - 1612, Dec. 1978. DOI: $10.1109 /$ TNS.1978.4329580

3. S. Kaya, E. Yilmaz, "Use of $\mathrm{BiFeO}_{3}$ layer as a dielectric in MOS based radiation sensors fabricated on a $\mathrm{Si}$ substrate," Nucl. Instrum. Methods Phys. Res., vol. 319, pp. 168 - 170, Jan. 2014.

DOI: 10.1016/j.nimb.2013.10.016

4. E. R. Benton, E. V. Benton, "Space radiation dosimetry in low-Earth orbit and beyond," Nucl. Instrum. Methods Phys. Res. Sec. B, vol. 184, no. 1-2, pp. 255 294, Sep. 2001.

DOI: 10.1016/So168-583X(01)o0748-o PMid: 11863032

5. S. Kaya, A. Jaksic, R. Duane, N. Vasovic, E. Yilmaz, "FET-based radiation sensors with $\mathrm{Er}_{2} \mathrm{O}_{3}$ gate dielectric," Nucl. Instrum. Methods Phys. Res. B, vol. 430, pp. 36 - 41, Sep. 2018. DOI: 10.1016/j.nimb.2018.06.007

6. E. Garcia-Moreno et al., "Floating Gate CMOS Dosimeter With Frequency Output," IEEE Trans. Nucl. Sci., vol. 59, no. 2, pp. 373 - 378, Apr. 2012. DOI: 10.1109/TNS.2012.2184301

7. G. Spiezia et al., "A New RadMon Version for the LHC and its Injection Lines,", IEEE Trans. Nucl. Sci., vol. 61, no. 6, pp. 3424 - 3431, Dec. 2014. DOI: $10.1109 /$ TNS.2014.2365046

8. R. Ferraro et al., "Design of a radiation tolerant system for total ionizing dose monitoring using floating gate and RadFET dosimeters," J. Instrum., vol. 12, no. 4, Apr. 2017.

DOI: 10.1088/1748-0221/12/04/C04007

9. M. Brucoli et al., "A complete qualification of floating gate dosimeter for CERN applications," in Proc. 16th Eur. Conf. Radiation and Its Effects on Comp. Syst. (RADECS), Bremen, Germany, 2016. DOI: 10.1109/RADECS.2016.8093162

10. S. Dahiya, K. Kumar, "Drain Current and Radiation Relation for MOSFET," Int. res. j. eng. tech., vol. 4, no. 5, pp. 1509 - 1511, May 2017.

Retrieved from:

https://www.irjet.net/archives/V4/i5/IRJETV4I5435.pdf Retrieved on: Aug. 11, 2019

11. M. M. Pejovic, "Processes in radiation sensitive MOSFETs during irradiation and post irradiation annealing responsible for threshold voltage shift," Radiat. Phys. Chem., vol. 130, pp. 221 - 228, Jan. 2017. DOI: 10.1016/j.radphyschem.2016.08.027

12. Nisha, R. Yadav, "Radiation Effect on MOSFET at Deep Submicron Technology," Int. J. Adv. Res. Computer Sci. Software Eng., vol. 3, no. 8, pp. 162-173, August 2013.

Retrieved from:

http://ijarcsse.com/Before August_2017/docs/papers Volume 3/8 August2013/V3I7-0560.pdf Retrieved on: Aug. 11, 2019

13. S. Stanic et al., "Radiation monitoring in Mrad range using radiation-sensing field-effect transistors," Nucl. Instrum. Methods Phys. Res. Sec. A, vol. 545, no. 1-2, pp. $252-260$, Jun. 2005. DOI: $10.1016 /$ j.nima.2005.01.347

14. J. Cesari, A. Barbancho, A. Pineda, G. Ruy, H. Moser, "Floating Gate Dosimeter Measurements at 4M Lunar Flyby Mission," in Proc. IEEE Radiation Effects Data Workshop (REDW), Boston (MA), USA, 2015. DOI: 10.1109/REDW.2015.7336710

15. S. Danzeca et al., "Characterization and Modeling of a Floating Gate Dosimeter with Gamma and Protons at Various Energies," IEEE Trans. Nucl. Sci., vol. 61, no. 6, pp. $3451-3457$, Nov. 2014. DOI: $10.1109 /$ TNS.2014.2364274

16. Radiation Sensor Information, iC Malaga, Alaró, Spain, 2019. Retrieved from: http://www.ic-malaga.com/servicios rad en.html; Retrieved on: Aug. 11, 2019

17. Sarayköy nükleer araştırma ve eğitim merkezi Tanitim kitabi, Türkiye atom enerjisi kurumu, Ankara, Türkiye, 2012. (Sarayköy nuclear research and training center - Promotion book, Turkey atomic energy agency, Ankara, Turkey, 2012.) Retrieved from: http://www.taek.gov.tr/tr/belgelerformlar/sanaem/SANAEM-Tanitım-Kitabi/lang,tr-tr/ Retrieved on: Aug. 12, 2019 